\title{
Density-Functional Calculations of Molecular Electron Affinities
}

\author{
Yuji Takahata $^{\mathrm{a} *}$, and Delano P. Chong ${ }^{\mathrm{b}}$ \\ ${ }^{a}$ Instituto de Química, Universidade Estadual de Campinas, \\ 13083-970 Campinas - SP, Brazil \\ ${ }^{\mathrm{b}}$ Department of Chemistry, The University of British Columbia, \\ 2036 Main Mall, V6T 1Z1, Vancouver - BC, Canada
}

\begin{abstract}
Afinidades eletrônicas de doze moléculas pequenas foram calculadas pela teoria de funcional de densidade empregando dois funcionais diferentes(B88-P86 e B3LYP) combinados com três conjuntos de bases diferentes(6-31++G**, 6-311++G** e aug-cc-pVTZ). O método de função de Green para camada na valência exterior também foi empregado para os cálculos de afinidades eletrônicas das moléculas. Duas melhores aproximações foram obtidas com as combinações entre (1)B88-P86 com 6-31++G**, e (2)B3LYP com 6-31++G**. As duas aproximações foram empregadas para cálculos de afinidades eletrônicas de algumas moléculas de tamanho média.

Electron affinities of twelve small molecules were calculated by density functional theory using two different functionals(B88-P86 and B3LYP) combined with three different basis sets(6$31++\mathrm{G}^{* *} ; 6-311++\mathrm{G}^{* *}$; aug-cc-pVTZ). Outer valence Green's function method is also employed for calculation of electron affinities of the molecules. The two most efficient approaches were found to be the combination of (1)B88-P86 with 6-31++G** basis set and (2)B3LYP with 6-31++G**. The two approaches were employed to calculate electron affinities of some medium size molecules.
\end{abstract}

Keywords: molecular electron affinities, density functional theory

\section{Introduction}

Electron affinities(EA) of atoms and molecules are one of the fundamental properties. They are as important properties as ionization energies. For instance, hardness is proportional to the difference between ionization energy and electron affinity of a species ${ }^{1}$. Theoretical studies on electron affinities have been rather limited due to theoretical and computational difficulties in comparison to treatment of ionization energies. Also, electron affinities are more difficult to measure experimentally than to measure ionization energies. Electron affinity is defined as the energy difference between the lowest state of the neutral and the lowest state of the corresponding negative ion. The electron affinity thus defined is the adiabatic electron affinity. Accurate calculation of electron affinities has been a challenge for theoretical and computational chemists.

Density functional theory(DFT) has been developed significantly in the last two decades. It is considered to be one alternative to the traditional methods such as ab initio MO, Green's function and propagator techniques. We are interested in investigating the reliability and usefulness of
DFT in calculating electron affinities(EA) for molecules. Zigler and Gutse found that the Local Density Approximation(LDA) in which a nonlocal correction proposed by Becke gave the best agreement with experiment ${ }^{2}$. More recently Boesch et al. ${ }^{3}$ reported that the three-parameter hybrid Hartree-Fock/density-functional B3LYP combined with the $6-311 \mathrm{G}(3 \mathrm{~d}, \mathrm{p})$ basis set is the most accurate for p-benzoquinone. Jursic ${ }^{4}$ studied the electron affinities of three radicals $\mathrm{CH} 3, \mathrm{CH} 3 \mathrm{O}$, and $\mathrm{CN}$ with over 20 functionals and concluded that the BLYP and BPW91 functionals gave the best results (average deviation of 0.06 and $0.04 \mathrm{eV}$ respectively). In addition, Tshumper and Schaefer ${ }^{5}$ calculated the electron affinities of 35 diatomic molecules with six different functionals and concluded that the BLYP provided the best agreement with experiment (average deviation of $0.21 \mathrm{eV}$ ). In our investigation we choose a number of diatomic and triatomic molecules together with several different approaches to calculate their electron affinities. From such investigation we can choose the best approach of calculating electron affinities. Then we apply the best approach for larger molecules.

*Telephone number: (019) 788-3103; Fax number: (19) 788-3023;

e-mail address: taka@iqm.unicamp.br 


\section{Methods of Calculations}

For our systematic study, we chose twelve diatomic and triatomic molecules with accurately determined electron affinities with uncertainty less than or equal to $0.008 \mathrm{eV}$. They are $\mathrm{CH}, \mathrm{CN}, \mathrm{FO}, \mathrm{SH}, \mathrm{SO}, \mathrm{OH}, \mathrm{C}_{2} \mathrm{H}, \mathrm{NCO}, \mathrm{SO}_{2}, \mathrm{O}_{3}$, NCS and SSO. Eight different theoretical approaches were tested. They are listed in Table 1. The first six approaches, I.A,-II.C, are based on density functional methods. They are six different combinations out of two different functionals; (I)B88-P86(pure DFT), and (II)B3LYP(hybrid), and three different basis sets; (A)6-31++G**, (B)6-311++G**, (C)aug-cc-pVTZ. The B88-P86 functional consists of Becke's 1988 functional(abbreviated B88) ${ }^{6}$ and Perdew's 1986 gradient-corrected functional $(\mathrm{P} 86)^{7}$. The B3 functional is the Becke's 3 parameter functional ${ }^{8}$ and LYP is Lee, Yang, and Parr's correlation functional ${ }^{9}$. The approaches III.A and III.B are both Outer Valence Green's function(OVGF) method ${ }^{10}$ with the two different basis sets $\mathrm{A}$ and $\mathrm{B}$. The basis set $\mathrm{A}$ is the 31 split-valence basis set and the basis set $\mathrm{B}$ is the 311 triple split-valence ${ }^{11}$. The basis set $\mathrm{C}$ is the Dunning's correlation consistent triplezeta basis set augmented with diffuse functions ${ }^{12}$. All calculation were performed by using the GAUSSIAN $94^{13}$ quantum chemistry computer program. The geometry of neutral(M) as well as anion( $\left.\mathrm{M}^{-}\right)$form of a molecule were fully optimized for each of the first six approaches, I.A.II.C. The total energies, $\mathrm{E}\left(\mathrm{M}_{\text {optimized }}\right)$ and $\mathrm{E}\left(\mathrm{M}_{\text {optimized }}^{-}\right)$, of $\mathrm{M}$ and $\mathrm{M}^{-}$correspond to those optimized geometries with the respective approach. In the Pople's notation, our calculations in the case of the approach I.A, for instance, can be described as follows;

for neutral $(\mathrm{M})$ molecule: B88-P86/6-31++G**//B88$\mathrm{P} 86 / 6-31++\mathrm{G}^{* *}$,

for anion $\left(\mathrm{M}^{-}\right)$: B88-P86/6-31++G**//B88-P86/6$31++\mathrm{G}^{* *}$,

where the specification before // is for the energy and that after // is for the geometry used. The geometry was optimized for $\mathrm{M}$ and $\mathrm{M}^{-}$separately. In the case of the

Table 1. Definition of the eight approaches, I.A, I.B, ... , III.B, tested for calculation of electron affinities of twelve small molecules. The eight approaches consist of the combination of the three different methods (I, II, III) listed in the first column and the three different Basis sets (A, B, C) listed in the first line.

\begin{tabular}{lccc}
\hline Method & Basis A & Basis B & Basis C \\
\hline I & I.A//I.A & I.B//I.B & I.C//I.C \\
II & II.A//II.A & II.B//II.B & II.C//II.C \\
III & III.A//Exptl. & III.B//Exptl. & - \\
\hline
\end{tabular}

where following notations are adopted: Basis $A=6-31++G^{* *}$; Basis $B=$ 6-311++G**; Basis C = aug-cc-pVTZ, and I = B88-P86(pure DFT); II = B3LYP(hybrid); III = Outer valence Green's function(ab initio).

The specification before// is for the energy and that after // is for the geometry used. approach II.B, as another example, the Pople's notation becomes;

for neutral(M) molecule: B3LYP /6311++G**//B3LYP /6-311++G**,

for $\operatorname{anion}\left(\mathrm{M}^{-}\right)$: B3LYP /6-311++G**//B3LYP /6$311++\mathrm{G}^{* *}$.

For the remaining four approaches, similar procedures to the cases of I.A and II.B were adopted. Electron affinity(EA) of the neutral molecule was calculated by taking the difference of the total energies of its neutral form of the molecule, $\mathrm{E}\left(\mathrm{M}_{\text {optimized }}\right)$, and that of anion, $\mathrm{E}\left(\mathrm{M}_{\text {optimized }}^{-}\right)$. Therefore, the calculated electron affinities are adiabatic electron affinities $\left(\mathrm{EA}_{\mathrm{ad}}\right)$ in case of the first six approaches, I.A.-II.C.

$$
\mathrm{EA}_{\mathrm{ad}}=\mathrm{E}\left(\mathrm{M}_{\text {optimized }}\right)-\mathrm{E}\left(\mathrm{M}_{\text {optimized }}^{-}\right)
$$

In the case of the last two approaches, III.A and III.B, of the OVGF method, experimental geometry of the neutral molecules $^{14,15}$, were employed both for the neutral form of molecule and its anion form of the molecule. The OVGF method calculates electron affinity with a single calculation on the neutral molecule. It does not require two calculations one for neutral and one for anion form of a molecule. The electron affinity calculated with OVGF method is, therefore, vertical( $\left.\mathrm{EA}_{\mathrm{vert}}\right)$.

$$
\begin{aligned}
\mathrm{EA}_{\mathrm{vert}}=\mathrm{E}(\text { exptl. geom. of neutral })- \\
\\
\mathrm{E}(\text { anion at the exptl. geom. of neutral })
\end{aligned}
$$

\section{Results and Discussion}

Table 2 summarizes the results of electron affinity calculations of the twelve small molecules with the eight different approaches, I.A-III.B. Roughly speaking, the average absolute deviation (AAD) of the first six approaches, I.A-II.C, is approximately $0.2 \mathrm{eV}$. The spread between the highest $(0.21 \mathrm{eV})$ and the lowest $(0.15 \mathrm{eV})$ among those six is only $0.06 \mathrm{eV}$. Since twelve cases is not a large enough sample size, we conclude that there is no substantial difference among these six approaches and that all the six approaches have almost the same quality. On the other hand, the larger errors, AAD's of ca. $0.3 \mathrm{eV}$, were found for the approaches III.A and III.B, both of which are outer valence Green's function methods. The difference of $0.1 \mathrm{eV}$ in the value of AAD's may be considered significant, albeit tentatively (because of our small sample size), since one wants to attain as high accuracy as possible in calculating electron affinities. As the Green's function method did not provide reliable molecular electron affinities in comparison to the other DFT methods, we will not consider any more the possibility of the use of the Green's function method for calculations of EA's below. Hence we direct our discussions only to the first six approaches(I.A-II.C).

Although the first six approaches have almost the same quality, we notice some slight differences among them. The 
Table 2. Electron affinities (EA)*, in eV, for the twelve simple molecules calculated by using the eight different approaches, I.A-III.B, which result from combinations of different functional and basis set (see Table 1 for the definition of the approaches).

\begin{tabular}{lccccccccc}
\hline & I.A & I.B & I.C & II.A & II.B & II.C $^{\text {b }}$ & III.A & III.B $^{\text {c }}$ & obs. $^{\text {d }}$ \\
\hline $\mathrm{CH}$ & 1.561 & 1.561 & 1.588 & 1.330 & 1.332 & 1.351 & 1.075 & 1.120 & $1.238 \pm 0.008$ \\
$\mathrm{CN}$ & 3.884 & 3.928 & 3.897 & 4.034 & 4.072 & 4.045 & 3.594 & 3.643 & $3.862 \pm 0.004$ \\
$\mathrm{FO}$ & 2.329 & 2.364 & 2.284 & 2.364 & 2.382 & 2.295 & 2.272 & 1.827 & $2.272 \pm 0.006$ \\
$\mathrm{SH}$ & 2.445 & 2.450 & 2.448 & 2.337 & 2.339 & 2.336 & 1.921 & 1.904 & $2.314344 \pm 0.000004$ \\
$\mathrm{SO}$ & 1.277 & 1.290 & 1.249 & 1.262 & 1.274 & 1.213 & 1.026 & 0.990 & $1.125 \pm 0.005$ \\
$\mathrm{OH}$ & 1.885 & 1.982 & 2.068 & 1.760 & 1.770 & 1.841 & 2.380 & 2.221 & $1.827670 \pm 0.000021$ \\
$\mathrm{C}_{2} \mathrm{H}$ & 3.180 & 3.179 & 3.158 & 3.134 & 3.128 & 3.109 & 3.180 & 2.781 & $2.969 \pm 0.006$ \\
$\mathrm{NCO}$ & 3.591 & 3.614 & 3.566 & 3.568 & 3.584 & 3.542 & 3.343 & $(\mathrm{a})$ & $3.609 \pm 0.005$ \\
$\mathrm{SO} 2$ & 1.533 & 1.546 & 1.438 & 1.625 & 1.634 & 1.496 & 0.629 & 0.606 & $1.107 \pm 0.008$ \\
$\mathrm{O}_{3}$ & 2.424 & 2.455 & 2.362 & 2.723 & 2.744 & 2.639 & 2.082 & 2.003 & $2.1028 \pm 0.0025$ \\
$\mathrm{NCS}$ & 3.536 & 3.557 & 3.519 & 3.506 & 3.523 & 3.486 & 3.022 & $(\mathrm{a})$ & $3.573 \pm 0.005$ \\
$\mathrm{SSO}^{2}$ & 2.206 & 2.218 & 2.091 & 2.347 & 2.347 & $(\mathrm{a})$ & 1.518 & 1.505 & $1.877 \pm 0.008$ \\
\hline AAD & 0.174 & 0.192 & 0.165 & 0.205 & 0.210 & 0.151 & 0.304 & 0.289 & $(0)$ \\
\hline Total CPU & $2.7 \mathrm{~h}$ & $3.8 \mathrm{~h}$ & $76.7 \mathrm{~h}$ & $2.9 \mathrm{~h}$ & $3.7 \mathrm{~h}$ & $76.0 \mathrm{~h}$ & $56.8 \mathrm{~m}$ & $3.8 \mathrm{~h}$ & \\
time & & & & & & & & & \\
\hline
\end{tabular}

*Adiabbatic electron affinity (Eq. 1) for approaches I.A-II.C; vertical electron affinity (Eq. 2) for approaches III.A and III.B.

a. Calculation was not successful; b. Eleven molecules only, no data of SSO is available; c. Ten molecules only, no data of NCO and NCS are available; d. Ref. 17; e. $\mathrm{AAD}=$ Average Absolute Deviation

two smallest average absolute deviation were achieved by the approach II.C and I.C respectively. The difference of the two AAD's is only $0.014 \mathrm{eV}(0.151 \mathrm{eV}$ for II.C and $0.165 \mathrm{eV}$ for I.C) and is not considered significant. However, we note that these two approaches, I.C and II.C, employ the basis $\mathrm{C}$ which is aug-cc-pVTZ whereas the other four approaches, I.A, I.B, II.A and II.B, employ $6-31++G^{* *}\left(\right.$ Basis A) or $6-311++G^{* *}$ (Bases B). The better performance of I.C and II.C is consistent with the quality of basis $\mathrm{C}$ being better than that of basis $\mathrm{A}$ and $\mathrm{B}$ for EA calculations. The performance of a basis set depends on the completeness profile of the basis, especially around the diffuse part in case of EA calculations. The completeness profile of aug-cc-pVTZ for carbon given by Chong ${ }^{16}$ shows its high quality as a basis set. The number of contracted Gaussian type basis in aug-cc-pVTZ(basis C) for the first row atoms is 46 , whereas the corresponding numbers of 6-31++G** (Basis A) and 6-311++G** (Bases B) are 19 and 23 respectively.

Total CPU times to calculate the twelve molecules with each approach are listed in the last line of Table 2. The smallest CPU time needed was with the approach III.A. The total CPU time required with the approaches I.A, I.B, II.A, II.B are roughly the same. The approaches I.C and II.C are the most time-consuming. The approaches I.C and II.C are roughly 20 times more time consuming than the rest of the approaches tested. The I.A, I.B, II.A, and II.B employ density functional methods together with the basis set 6$31++\mathrm{G}^{* *}$ or $6-311++\mathrm{G}^{* *}$. The I.C and II.C use the basis set aug-cc-pVTZ which is substantially larger basis set (more than twice) than $6-31++\mathrm{G}^{* *}$. Pople's type of basis sets, such as Basis Sets A and B used here, are especially efficient for geometry optimization, for the following reasons: (a) In the basis A and B, the primitive valence $s$ and p GTO's share the same set of exponents. This saves cpu time for the evaluation of primitive integrals. (b) Pople's basis sets use segmented contraction scheme, which saves cpu time in integral transformation. (c) Basis A and B have only half as many CGTOs as Basis C. The approach III.A consumed the least computing time of all. Method III.A did not require too much CPU time because experimental geometry was used for both parent and anion(i.e. no optimization of geometry). On the other hand, all approaches that belong to the methods I and II required geometry optimization. We prefer not choose III.A as our best approach due to the low accuracy in comparison to the other approaches as discussed previously. We have to choose the best approach out of the six, I.A-II.C. From Table 2, we conclude that all six have about the same AAD, but that, because of the large increase in CPU times, basis set $\mathrm{C}$ is not recommended for general use. The other four are about equal, with basis A being more economical. Therefore I.A and II.A are chosen as our recommended approaches which will be used bellow. 
Since we found that I.A and II.A are the recommended approaches out of the eight tested, we used them to calculate electron affinities of some larger molecules than any of the ones tested previously. Table 3 lists electron affinities of some medium size molecules. The molecules in Table 3 are grouped into two categories: Group A and Group B. Group A consists of five molecules. All the Group A molecules belong to $\pi$-system. The Group B molecules consists of two molecules that are fluorine compounds with $\sigma$-system. When we used the approach I.A, we obtained that average absolute deviation(AAD) for the Group A molecules is $0.29 \mathrm{eV}$, while AAD of the Group B molecules is $1.26 \mathrm{eV}$. Agreement between theory and experiment for the Group A molecules is reasonable, while the large errors were found for the Group B molecules. The EA's calculated with the approach II.A are very much similar to those calculated with I.A. There is no substantial change on the calculated EA's going from the method I(B88-P86) to the method II(B3LYP). Finally we calculated vertical electron affinities using II.A just for the sake of comparison. Experimental geometry ${ }^{14,15}$ was employed for the calculation of vertical electron affinity. Very good agreements between theory and experiment were obtained for $\mathrm{p}$-benzoquinone and p-fluoranil(tetrafluoro-p-benzoquinone). The values of adiabatic electron affinities of $\mathrm{p}$-benzoquinone and $\mathrm{p}$ fluoranil calculated Boesh et $a l^{3}$ are close to those of vertical electron affinity listed in Table 3 . They used an approach similar, but not identical, to our II.A. Agreement between theory and experiment for maleicanhydride and 1,4-naphtoquinone are fair. Rienstra-Kiracofe and Schaefer III $^{18}$ calculated EA of tetracyanoethylene to be $3.51 \mathrm{eV}$ using DZP++B88-P86. Our corresponding values(Table 3) are very similar to this. The AAD of vertical electron affinity calculated with II.A is $0.11 \mathrm{eV}$, which is about $40 \%$ of the AAD of adiabatic electron affinity calculated either I.A or II.A. Observed EA's are adiabatic. Why calculated vertical EA's agree to experiment better than the calculated adiabatic EA's is not known. The AAD's of the Group B molecules are all greater than $1.1 \mathrm{eV}$. Neither I.A nor II.A are capable of calculating reasonable value of EA. Ziegler and Gutsev calculated the adiabatic electron affinity $\left(\mathrm{EA}_{\mathrm{ad}}\right)$ of $\mathrm{SF}_{4}$ to be $1.40 \mathrm{eV}$ using LSDA, and $2.56 \mathrm{eV}$ using LSD/NL ${ }^{19}$. King et al. ${ }^{20}$ also calculated adiabatic electron affinity of $\mathrm{SF}_{4}$. They obtained $2.54 \mathrm{eV}$ using DZP++B88P86 and $2.45 \mathrm{eV}$ using DZP++B3LYP. Our values $1.95 \mathrm{eV}$ of the adiabatic electron affinity of $\mathrm{SF}_{4}$ calculated with the approaches I.A and II.A are about $0.5 \mathrm{eV}$ smaller than those obtained by King et al. These differences are due to the difference of the basis set used. There are two experimental data for $\mathrm{SF}_{4}$ available in the literature: $1.5 \pm 0.2 \mathrm{eV}^{21}$ and $2.35 \pm 0.1 \mathrm{eV}^{22}$. Our calculated value of EA, $1.95 \mathrm{eV}$, of $\mathrm{SF}_{4}$ is very close to the average of the two experimental

Table 3. Electron affinities(EA), in eV, for some molecules calculated by using the approach I.A (B88-P86/6-31++G**) and approach II.A (B3LYP/6$\left.31++G^{* *}\right)$.

\begin{tabular}{|c|c|c|c|c|}
\hline Method & I.A//I.A ${ }^{\mathrm{a}}$ & II.A//II.A ${ }^{\mathrm{a}}$ & II.A//Exptl. ${ }^{\mathrm{b}}$ & $\begin{array}{c}\text { Observed } \\
\mathrm{EA}^{17}\end{array}$ \\
\hline \multicolumn{5}{|l|}{ Molecule } \\
\hline \multicolumn{5}{|l|}{ Group A } \\
\hline p-fruoranil & 2.61 & 3.04 & 2.74 & $2.70 \pm 0.1$ \\
\hline p-benzoquinone & 2.27 & 2.17 & 1.88 & $1.91 \pm 0.06$ \\
\hline Maleicanhydride & 1.78 & 1.72 & 1.34 & $1.44 \pm 0.1$ \\
\hline 1,4-naphtoquinone & 2.13 & 2.00 & 1.56 & $1.81 \pm 0.1$ \\
\hline Tetracyano-Ethylene & 3.49 & 3.48 & 3.3 & $\begin{array}{c}3.17 \pm 0.2^{\mathrm{d}} \\
2.9 \pm 0.1^{\mathrm{e}} \\
2.3 \pm 0.3\end{array}$ \\
\hline $\mathrm{AAD}^{\mathrm{c}}$ & 0.29 & 0.28 & 0.11 & \\
\hline \multicolumn{5}{|l|}{ Group B } \\
\hline $\mathrm{SF}_{4}$ & 1.95 & 1.95 & 0.2 & $\begin{array}{c}1.5 \pm 0.2^{\mathrm{f}} \\
2.35 \pm 0.1^{\mathrm{g}}\end{array}$ \\
\hline $\mathrm{SF}_{6}$ & 3.12 & 2.83 & -0.3 & $1.05 \pm 0.1$ \\
\hline $\mathrm{AAD}^{\mathrm{c}}$ & 1.26 & 1.12 & 1.33 & \\
\hline
\end{tabular}

a. Adiabatic electron affinity (Eq. 1); b. Vertical electron affinity (Eq. 2).

The separation before // is for the energy and that after // is for the geometry used.

c. $\mathrm{AAD}=$ Average Absolute Deviation; d. Ref. 24; e. Ref. 25; f. Ref. 21; g. Ref. 22. 
values. King et al. ${ }^{20}$ calculated the adiabatic electron affinity of $\mathrm{SF}_{6}$ to be $3.00 \mathrm{eV}$ using the approach DZP++B88-P86 and $2.66 \mathrm{eV}$ using approach DZP++B3LYP. These values are close to our corresponding adiabatic values of approaches I.A and II.A listed in Table 3. Experimental electron affinity of $\mathrm{SF}_{6}$ is $1.05 \pm 0.1 \mathrm{eV}$ which is approximately $2 \mathrm{eV}$ lower than the calculated values. Klobukowski et al. ${ }^{23}$ calculated the electron affinity of $\mathrm{SF}_{6}$ to be $1.78 \mathrm{eV}$ using B3LYP with large basis sets that include f-type polarization functions. To get better agreement between theory and experiment in the calculation of EA for the kind of Group B molecules that we studied in Table 3, we have to use large basis that include up to f-functions. The entire Group A molecules in Table 3 belong to $\pi$-system, while those in Group B belong to $\sigma$-system. Electron affinity of $\pi$-systems seem to be calculated more accurately than that of $\sigma$-system by DFT.

\section{Acknowledgment}

One of us(YT) thanks FAPESP - Fundaçao de Amparo à Pesquisa do Estado de São Paulo for the post-doctoral fellowship and CNPq for the financial aid. We thank CENAPAD-SP for the computer facilities.

\section{References}

1.Parr, R.G.; Yang,W. In Density-functional theory of atoms and molecules, Oxford University Press, Oxford, p. 95-98, 1989.

2.Ziegler,T.; Gutsev,G.L. J.Compt.Chem. 1992, 13, 70.

3. Boesch, S.E.; Grafton, A.K.; Wheeler, R.A. J. Phys. Chem. 1996, 100, 10083.

4. Jursic, B.S. J. Mol. Struct.(THEOCHEM) 1997, 394, 19.

5. Tshumper, G.S.; Schaefer III, H.F. J. Chem. Phys. 1997, 107, 2529.

6. Becke, A.D. Phys. Rev. 1988, A38, 3098.

7. Perdew, J.P. Phys. Rev. 1986, B33, 8822.

8. Becke, A.D. J. Chem. Phys. 1993, 98, 5648.

9. Lee, C.;Yang, W.; Parr, R.G. Phys. Rev. 1988, B37, 785.

10. Ortiz, J.V. J. Chem. Phys. 1988, 89, 6348.

11. Hehre, W.J.; Radom, L.; Schleyer, P.v.R.; Pople, J.A. Ab initio Molecular Orbital Theory, Jhon Wiley \& Sons; New York, 1986.
12. Kendall, R.A.; Dunning Jr., T.H.; Harrison, R.J. J.Chem. Phys. 1992, 96, 6796.

13. Frish, M.J.; Trucks, G.W.; Schlegel, H.B.; Gill, P.M.W.; Johnson, B.J.; Robb, M.A.; Cheeseman, J.R.; Keith, T.A.; Peterson, G.A.; . Montgomery, J.A.; Ragavachari, K.; Al-Laham, M.A.; Zakrzewski, V.G.; Ortiz, J.V.; Foresman, J.B.; Cisolwski, J.; Stefanov, B.B.; Nanayakkara, A.; Peng, C.Y.; Ayara, P.Y.; Chen, W.; Wong, M.W.; Andres, J.L.; Replogle, E.S.; Gomperts, R.; Martin, R.L.; Fox, D.J.; Binkley, J.S.; Defrees, D.J.; Baker, J.; Stewart, J.P.; Head-Gordon, M.; Gonzalez, C.; Pople, J.A. Gaussian 94, Gaussian, Inc., Pittsburgh, PA, 1995.

14. Hellwege, K.L., ed., Landolt-Börnstein numerical data and functional relation ship in science and technology, New Series, Group II, v. 7. Springer, Berlin, 1976.

15. Madelung, O., ed., Landolt-Börnstein numerical data and functional relation ship in science and technology, New Series, Group II, v. 21., Springer, Berlin, 1992.

16. Chong, D.P. Can. J. Chem. 1995, 73, 79. There is a small error in the middle frame of Fig. 1. The d-type completeness profile should be identical to that of the bottom frame of Fig. 1.

17. Lide, D.R.; Frederikse, H.P.R., eds.; CRC Handbook of Chemistry and Physics, 1995-1996, 76th Edition, CRC Press, Boca Raton, p.10-182 -10-188.

18. Private communication from Rienstra-Kiracofe, Jonathan; Scaefer III, H.F. 1998.

19.Ziegler,T.; Gutsev, G.L. J. Chem. Phys. 1992, 96, 7623.

20. King, R.A.; Galbraith, J.M.; Schaefer III, H.F. J. Phys. Chem. 1996,100,6061.

21. Viggiano, A.A.; Miller, T.M.; Miller, E.S.; Morris, R.A.; Van Doren,J.M.;Paulson, J.F. J. Mass Spectrom. Ion Processes 1991, 109, 327.

22. Babcock, L.M.; Streit, G.E. J. Chem. Phys. 1981, 75, 3864.

23. Klobukowski, M.; Dierksen, G.H.F.; García de la Veja, J.M. In: Advances in Quantum Chemistry, v. 28, Academic Press, p.189, 1997.

24. Chowdhury,S.; Kebarle, P. J. Am. Chem. Soc. 1986, 108, 5453.

25. Farragher, A.L.; Page, F.M. Trans Faraday Soc. 1967, 63, 2369.

Received: November 3, 1998

FAPESP helped in meeting the publication costs of this article 